\title{
Subtotal supracricoid laryngectomy: changing in indications, surgical techniques and use of new surgical devices ${ }^{\hbar}$
}

\author{
Giuditta Mannelli ${ }^{a, *}$, Giuseppe Meccariello ${ }^{a}$, Alberto Deganello ${ }^{a}$, \\ Francesca Romana Fiorini ${ }^{a}$, Fabiola Paiar ${ }^{b}$, Oreste Gallo ${ }^{a}$ \\ a First Clinic of Otolaryngology, Department of Surgery and Translational Medicine, University of Florence, Via Largo Brambilla 3, Florence, Italy \\ ${ }^{\mathrm{b}}$ Department of Radiotherapy, University of Florence, Viale G.B. Morgagni, 85, Florence, Italy
}

\section{A R T I C L E I N F O}

Article history:

Received 15 May 2014

\begin{abstract}
A B S T R A C T
Purpose: The aim of this study is to evaluate the evolution of supracricoid partial laryngectomy (SCPL) in indications, surgical techniques and outcomes through last decades. Materials and methods: A retrospective analysis of 146 patients affected by laryngeal cancer treated with SCPL was carried on. We defined: (1) group A, 100 patients treated by cold instruments between 1995 and 2004; (2) group B, 46 patients treated by harmonic scalpel between 2005 and 2010. Complications rate, and functional and oncological results were documented and a comparison between the two groups was made; histopathological analysis of surgical margins was evaluated and correlated with local incidence of recurrence.

Results: Significant differences in age mean-value $(p=0.02)$, T classification $(p=0.007)$, and in indication for more advanced-staged patients were found in group B $(p=0.001)$. Surgical procedure was shorter in group B $(p<0.001)$, with shorter swallowing recovery $(p=0.003)$. Oncological outcomes did not report any significant differences. Group B showed a higher incidence of post- operative arytenoid edema $(p=0.03)$ associated with a lower rate of pneumonia $(p=0.038)$. Despite a higher rate of close or positive-margins found in group B no higher incidence of local-recurrence was reported $(p=0.02)$ compared to group A.

Conclusions: We documented changing in indications and surgical technique for SCPL because of the development of modern diagnostic techniques and the introduction of low-thermal injury device allowing a more challenging tumor excision as well as with a shorter swallowing recovery in our series.
\end{abstract}

(c) 2014 Elsevier Inc. All rights reserved.

\section{Introduction}

Treatment options for laryngeal cancer include different radiation and surgical techniques, whose choice depends on extension of the disease, clinical presentation and general health of patients. The main concern is tumor control together with organ function preservation when it is possible. Supracricoid partial laryngectomy (SCPL) provides a good surgical

\footnotetext{
Acknowledgments and conflict of interest: None declared. Authors disclose any financial, consultant, institutional and other relationships of interest.

* Corresponding author at: First Clinic of Otorhinolaryngology, Department of Surgery and Translational Medicine, University of Florence, Via Largo Brambilla n. 3, CAP 50134, Florence, Italy. Tel.: + 39055 7947112; fax: +39 0557947939.

E-mail address: mannelli.giuditta@gmail.com (G. Mannelli).
} 
alternative to the conventional radiotherapy and total laryngectomy in the treatment of specific glottic and supraglottic cancers [1-4]. Supracricoid partial laryngectomy was initially introduced by Hofmann-Saguez in 1950 [5] and further discussed by Mayer and Rieder in 1958 [6]. In addition, the procedure was refined and found a practical validity and application by Labayle and Bismuth in 1971 [3], Alajmo in 1971 in Florence [7], and Piquet et al. in 1972 [8]. All of these surgeons proposed supracricoid partial laryngectomy as valid surgical alternative to total laryngectomy in elective T1 and T2 laryngeal cancer patients, describing it as a technique able to ensure recovery from the disease and laryngeal function preservation together.

So far, surgical indications have been changed and extended to more advanced staged cancers $[1,4,9]$ because of the improvement of diagnostic technologies such as CAT scan and MRI [10,11], a more precise stage of the disease by endoscopic fiberoptic together with fluorescence or narrow banding imaging (NBI) exams [12-14], as well as because of the advent of new surgical devices [15] which allowed the improvement of the intraoperative management of the operation and the surgical technique as well. All of these changes, together with the help of frozen section analysis in the intraoperative control of resection margins [16,17], have determined a radical turn in the management of these laryngeal cancer patients during the last 40 years, furthermore, with the new concept that recurrent irradiated cancer has to be treated as a primitive one, with no worsening in staging status and surgical indication, with no absolute contraindication for SCPL [18-20].

Accordingly, here we critically evaluated our personal experience in the last decades with SCPL with the aim to underline changing in indications, potential improvement in functional and oncological results and the impact of new surgical devices recently used at out Institute.

\section{Materials and methods}

\subsection{Study population}

We re-evaluated functional and oncological outcomes from 146 consecutive laryngeal cancer patients, treated at our academic tertiary referral center (First Clinic of Otorhinolaryngology, University of Florence, Azienda Ospedaliero Universitaria Careggi, Italy) between 1995 and 2010. The protocol for the retrospective controlled clinical study was approved by the Institutional Review Board, and it was conducted in accordance with all accepted standards for human clinical research. All patients gave written informed consent prior to study enrollment.

All of these patients underwent supra-cricoid partial laryngectomy (crico-hyoid-epiglotto-pexy CHEP or crico-hyoid pexy CHP) [2,3] as primary or salvage treatment for squamous-cell laryngeal cancer. The principal exclusion criteria counted patients with T4 lesions, low index of Karnofsky ( $\leq 80 \%)$, respiratory deficiency, cardiopathies, diabetes, obstructive bronco-pneumapathies, arthritis, neurological deficits, not eligible for open laryngeal conservative approaches [21,22].

To follow our aim, we divided SCPLs into two different groups: (1) group A: 100 patients, treated between 1995 and 2004, who underwent tumor excision by traditional cold instruments; (2) group B: 46 patients, treated between 2005 and 2010, where primary cases were treated by using harmonic scalpel, while the use of warm instruments was avoided for the remaining 7 salvage cases. We excluded from the histopathological analysis salvage SCPLs that account for a total of 17 patients, 10 of them belong to group A and the remaining 7 patients belong to group $\mathrm{B}$. We decided to perform this comparison between two different time periods in order to analyze and compare changing in surgical indications and technique, and their possible influence on postoperative outcomes and histopathological parameters, because 2005 saw the introduction of harmonic scalpel as a new device in this surgical procedure at our Clinic and the use of more fully-developed diagnostic instruments (i.e.: new CAT scan and MRI) made the staging procedure more accurate, helping in the better classification of laryngeal cancer patient and in giving indications for conservative open partial laryngectomy.

Tumor excision was carried out in accordance with standard surgical practice and indications of head and neck surgical oncology, in the strict observance of sterile conditions in the operating room and in general anesthesia regimen. The harmonic scalpel always presented similar setting when used in each surgical procedure: $55.5 \mathrm{kHz}$ alternative current, with a dissecting tip blade $10 \mathrm{~mm}$ long and gently curved. It is able to cut and coagulate at a lower temperature $\left(\max 150^{\circ} \mathrm{C}\right)$ using mechanical vibration at 55,500 cycles per second [23,24]. We avoided the use of harmonic scalpel in salvage procedure to reduce the high potential incidence of diffuse edema on irradiated field.

A classic scalpel, blade number 15 was used during the cold procedure in group A and for the 7 salvage cases of group B.

\subsection{Re-evaluation of functional and oncological outcomes of the historical series}

We applied a functional study protocol to analyze clinical parameters of each patient during their admission. We calculated from patients' hospital records the following data: (1) operation mean duration time, expressed in minutes; (2) difference in preoperative and immediate postoperative hemoglobin $(\mathrm{Hb})$ mean value $(\mathrm{g} / \mathrm{dL})$; (3) mean duration time of drainage removal in patients who underwent neck dissection (ND) (mL); (4) total drainage production in patients who underwent ND (mL); (5) decannulation mean time (day); and (6) mean time of removal of naso-gastric-feeding tube (NGT) (day).

To compare functional outcomes, parameters about voice results, expressed in voice-handicap-index values (VHI) [25-27], and dysphagia recovery, analyzed by MD Anderson Dyshagia Inventory (MDADI) [28,29], were evaluated together with the performance of fiberoptic endoscopic analysis, videolaryngeal stroboscopy after the removal of the tracheocannula and videofluoroscopy (VDFS) test in patients near to restarting oral feeding [30,31].

Outpatient clinical follow-up data were collected and they included monthly clinical examination with performance of fiberoptic endoscopy during the first year after surgery, each 2 months during the second year, every 3 months during the third year then, each 4 and 6 months during the last 2 years of follow-up. Imaging study was always complementary to clinical examination, by computer-tomography-scan of neck and chest.

Considering the day of the salvage surgery as the starting day of the observation, follow-up was for a minimum of 2 years or until death (mean 45 months; minimum 6, maximum 180). 
Follow-up end points included evidence of local or regional recurrence, death from disease or from other causes.

2.3. Histological re-evaluation of excised margins from the 129 historical cases by a hypothetical model

We retrospectively re-evaluated histopathological reports for each patient, from the pool of 129 primary SCPLs patients, and we reclassified them according to surgical margins status in: close (within 1-5 $\mathrm{mm}$ far from the inked margin edge), negative ( $\geq 5 \mathrm{~mm}$ far from the inked margin edge) and positive margins (distance from the inked margin edge $<1 \mathrm{~mm}$ ) [32].

For margins from patients treated by low-thermal-injury devices a histological unreadable tissue area (high thermal injury) was identified, and pathologists evaluated in these cases surgical margins as the distance from the true inked margin to the closest cancer cell belonging to the closest cluster of malignant cells, considering the line between the unreadable and readable area as surgical margins status evaluation limit [33].

The re-interpretation of each histopathological report was carried on by referring to a quantitative model recently published by us (Table 1) [15]. Finally, the surgical margin status was correlated to the incidence of local recurrence as found by follow-up data.

\subsection{Statistics}

Statistical analysis was performed by STATA (Stata Corporation, College Station, TX, USA). Statistical significance was defined as $p<0.05$. Kaplan-Meyer disease-free survival was used to compare results among different groups.

\section{Results}

\subsection{Study population}

Clinical data of each patient-group and their statistical analysis are summarized in two different tables in order to simplify the visualization of their results (Tables 2 and 3). The sites and stage of the tumor have been classified according to the AJCC TNM, 2010 [34].

Among the primary treatment groups our results showed the presence of a significant difference in age mean-value between the two groups ( $p=0.02)$, where group A presented a mean value age of 57.4 years $\pm 9.1 \mathrm{SD}$ (standard deviation), with a range of 24-70, while group B included a pool of older patients, with an age mean value of 61.2 years $\pm 7.2 \mathrm{SD}$, and 45 and 75 years as minimum and maximum values, respectively.

Table 1 - Ranges, mean values and confident interval with standard deviation of measurable distances between calibrated margins )Reported from Mannelli et al. [13] [Epub ahead of print]).

Harmonic scalpel-scalpel

$\begin{array}{ll}\text { Range } & 2.02-2.50 \mathrm{~mm} \\ \text { mean value } & 2.226 \mathrm{~mm} \\ \mathrm{CI} \pm \mathrm{DS} & 2.08510-2.36748 \pm 0.15266\end{array}$

No statistical differences where found in gender $(p=0.11)$, alcohol consumption ( $p=0.071)$, smoke habits $(p=0.731)$, and adjuvant postoperative radiotherapy $(p=0.24)$ among the two study groups.

Group B presented a higher number of more advanced-staged laryngeal tumors, CT3 $(28,2 \%)$, treated by open partial supracricoid laryngectomy than those performed at the same diagnostic stage in group A (20\%), this value resulted to be statistically significant in our analysis $(p=0.02)$. Moreover, the whole difference in $\mathrm{T}$ classification among the two groups was statistically outstanding $(p=0.007)$, with a rise in number of more advanced patients who underwent this type of partial surgery, in association with an increasing in indications for CHEP than for CHP during the second period of analysis ( $p=0.001)$.

Among the salvage treatment groups our results showed no statistical differences in age mean-value between the two groups $(p=0.15)$, where group A presented a mean value age of 57.60 years $\pm 5.48 \mathrm{SD}$, with a range of $48-66$, while group $\mathrm{B}$ included a pool of older patients, with an age mean value of 60.71 years $\pm 6.42 \mathrm{SD}$, and 52 and 68 years as minimum and maximum values, respectively; neither significant $p$ values was found in gender $(p=0.48)$, alcohol consumption ( $p=0.33$, smoke habits $(p=0.19$.) among the two study groups.

Our results showed that before being treated with radiotherapy, 7 (41\%) patients were initially seen with T1a carcinoma, 5 (29\%) with T1b, 4 (24\%) with T2 glottic cancer and 1 (6\%) with T2 supraglottic carcinoma. Disease in all patients was clinically classified as N0, so that the series had 12 (70.5\%) patients with stage I, and 5 (29.5\%) patients with stage II. All tumors were biopsy proven squamous cell carcinomas. Patients were treated with curative radiation therapy; the total amount of laryngeal dose per patients ranged from 65 to $70 \mathrm{~Gy}$ (mean $66 \mathrm{~Gy}$ ) fractionated over a period of 6 to 7 weeks. In the patients with stage II, neck lymphatic area of levels II-IV was included in the target volume with a dose of $50 \mathrm{~Gy}$.

Table 2 - Clinical characteristics of 129 historical cases.

\begin{tabular}{|c|c|c|c|}
\hline & Group A (90) & Group B (39) & $\begin{array}{l}p \\
\text { value }\end{array}$ \\
\hline $\begin{array}{l}\text { Age } \\
\text { (mean value, years) }\end{array}$ & 57.4 & 61.2 & 0.02 \\
\hline Gender: male:female & 82 (92.4\%): 8 (7.6\%) & 39 (100\%): 0 (0\%) & 0.11 \\
\hline $\begin{array}{l}\text { Alcohol } \\
\text { consumptiom }\end{array}$ & 41 (45.6\%) & $10(25.5 \%)$ & 0.071 \\
\hline Smoke habit & 71 (78.9\%) & $26(66.7 \%)$ & 0.731 \\
\hline $\begin{array}{l}\text { postoperative } \\
\text { radiotherapy }\end{array}$ & $3(3.3 \%)$ & $4(10.3 \%)$ & 0.24 \\
\hline cT1a & $16(17.8 \%)$ & $1(2.6 \%)$ & 0.02 \\
\hline cT1b & $8(8.9 \%)$ & $8(20.5 \%)$ & \\
\hline cT2 & $47(52.2 \%)$ & $19(48.7 \%)$ & \\
\hline сT3 & $18(20 \%)$ & $11(28.2 \%)$ & \\
\hline cT4a & $1(1.1 \%)$ & 0 & \\
\hline $\mathrm{CHP}^{\mathrm{a}}$ & $73(81.1 \%)$ & $12(30.8 \%)$ & 0.001 \\
\hline $\mathrm{CHEP}^{\mathrm{a}}$ & 17 (18.9\%) & $27(69.2 \%)$ & \\
\hline Local recurrences & $17(18.9 \%)$ & $8(20.5 \%)$ & 0.27 \\
\hline $\begin{array}{l}\text { Salvage total } \\
\text { laryngectomy }\end{array}$ & $13(76 \%)$ & $5(62.5 \%)$ & 0.78 \\
\hline
\end{tabular}


Table 3-Clinical characteristics of 17 salvage SCPL historical cases.

\begin{tabular}{|c|c|c|c|}
\hline & Group A (10) & Group B (7) & $\begin{array}{l}p \\
\text { value }\end{array}$ \\
\hline Age (mean value, years) & 57.60 & 60.71 & 0.15 \\
\hline Gender: male:female & 8 (80\%): 2 (20\%) & 7 (100\%): 0 (0\%) & 0.48 \\
\hline Alcohol consumptiom & $4(40 \%)$ & $1(14 \%)$ & 0.33 \\
\hline Smoke habit & $7(70 \%)$ & $4(57 \%)$ & 0.19 \\
\hline cT1a & $5(50 \%)$ & $2(28 \%)$ & 0.32 \\
\hline cT1b & $3(30 \%)$ & $2(28 \%)$ & \\
\hline cT2 & $2(20 \%)$ & $3(44 \%)$ & \\
\hline $\mathrm{rT} 1 \mathrm{a}^{\mathrm{a}}$ & $0(0 \%)$ & $1(14 \%)$ & 0.75 \\
\hline $\mathrm{rT} 1 \mathrm{~b}^{\mathrm{a}}$ & $3(30 \%)$ & $1(15 \%)$ & \\
\hline $\mathrm{rT} 2^{\mathrm{a}}$ & $5(50 \%)$ & $4(57 \%)$ & \\
\hline $\mathrm{rT}^{\mathrm{a}}$ & $2(20 \%)$ & $2(28 \%)$ & \\
\hline Stage I & $8(80 \%)$ & $4(57 \%)$ & 0.39 \\
\hline Stage II & $2(20 \%)$ & $3(44 \%)$ & \\
\hline Stage III & $0(0 \%)$ & $0(0 \%)$ & \\
\hline rStage I ${ }^{a}$ & $3(30 \%)$ & $1(14 \%)$ & 0.46 \\
\hline rStage II $^{\mathrm{a}}$ & $5(50 \%)$ & $4(57 \%)$ & \\
\hline rStage III ${ }^{a}$ & $2(20 \%)$ & $2(28 \%)$ & \\
\hline salvage $\mathrm{CHP}^{\mathrm{b}}$ & $8(80 \%)$ & $4(57 \%)$ & 0.59 \\
\hline salvage $\mathrm{CHEP}^{\mathrm{b}}$ & $2(20 \%)$ & $3(44 \%)$ & \\
\hline Neck dissection & $2(20 \%)$ & $2(28 \%)$ & 1 \\
\hline Local Recurrences & $1(10 \%)$ & $0(0 \%)$ & 1 \\
\hline $\begin{array}{l}\text { Salvage total } \\
\text { laryngectomy }\end{array}$ & $1(10 \%)$ & $0(0 \%)$ & 1 \\
\hline \multicolumn{4}{|c|}{$\begin{array}{l}\text { a The sites and stage of the tumor have been classified according to } \\
\text { the AJCC TNM, } 2010 \text { [31], where "r" means "recurrence". } \\
\text { b CHP (crico-hyoid pexy) and CHEP (crico-hyoid-epiglotto-pexy) [5,6]. }\end{array}$} \\
\hline
\end{tabular}

All radiotherapy failures were biopsy proven; contrastenhanced CT scan of the neck and direct microlaryngoscopy under general anesthesia assessed the extension of the recurrent disease, and thoracic CT scan ruled out pulmonary metastases.

There was no statistical significance in $\mathrm{CT}$ classification of the primary tumor $(p=0.32)$, rT classification of the recurrence $(p=0.75)$, clinical stage of the pre-radiotherapy treatment tumor $(p=0.39)$ and of the recurrence after radiotherapy failure $(p=0.46)$, among group A and B.

In $8(47 \%)$ patients with recurrent tumors, the restaging after radiotherapy was unchanged, while in the remaining 11 patients an upstaging was recorded (53\%): in 5 (29.5\%) patients we had a progression from stage I to stage II, in 3
(17.6\%) patients from stage I to stage III, and in 1 (5.9\%) patient from stage II to stage III. All 17 patients agreed with the procedure and signed an informed consent form to undergo SCPL: CHP was performed in 12 (70.6\%) cases, while the remaining 5 (29.4\%) patients underwent CHEP. Neck dissection was performed in $4(24 \%)$ cases, homolateral elective selective neck dissection (SND) of levels II-IV was performed in 3 NO patients, a therapeutic homolateral functional neck dissection of levels II-V was performed in 1 patient clinically N1. No significant $p$ values were shown by statistical analysis of salvage SCPL $(p=0.59)$ and neck dissection $(p=1)$.

\subsection{Re-evaluation of functional and oncological outcomes of the historical series}

\subsubsection{Functional assessment}

Perioperative, intraoperative and postoperative main functional parameters of the 146 SCPLs are summarized in Table 4.

Among these two groups, there was a significant difference in operation mean duration time between the two groups $(p<0.001)$, with a significant reduction of about 26.76 minutes in surgery's duration mean time in group B than in group A. No statistical significances were found in blood loss, expressed in preoperative and postoperative $\mathrm{Hb}$ values $(\mathrm{g} / \mathrm{dL})$, neither in mean time of drainage removal or drainage amount production $(\mathrm{mL})$ in those patients who underwent complementary surgical neck dissection, nor in decannulation mean time (days). On the other hand, naso-gastric-feeding tube (NGT) was removed earlier in group B than in group A, presenting a statistical $p$ value of 0.003 , associated with a faster recover of oral feeding intake.

Among the salvage treatment groups no statistical significances were found in operation mean duration time (minutes), blood loss, expressed in preoperative and postoperative $\mathrm{Hb}$ values $(\mathrm{g} / \mathrm{dL})$, neither in mean time of drainage removal or drainage amount production $(\mathrm{mL})$ in those patients who underwent complementary surgical neck dissection, nor in decannulation mean time (days) and naso-gastric-feeding tube (NGT) removal between the two groups analyzed.

No significant differences were encountered in terms of VHI and MDADI scores in both two historical series analyzed. Swallowing function was studied also under videofluoroscopy vision 3 weeks after surgery, by following the secretion severity scale [35]. Patients were divided into three groups:

Table 4 - Summary of functional parameters analyzed retrospectively of 129 historical cases.

\begin{tabular}{|c|c|c|c|c|}
\hline & \multicolumn{2}{|l|}{ Primary cases } & \multicolumn{2}{|l|}{ Salvage cases } \\
\hline & Group A (90) & Group B (39) & Group A (10) & Group B (7) \\
\hline Operation mean duration time (minutes) & $121.43 \pm 35.57 \mathrm{SD}$ & $94.67 \pm 25.01 \mathrm{SD}$ & $109.20 \pm 11.02 \mathrm{SD}$ & $103.14 \pm 5.81 \mathrm{SD}$ \\
\hline Difference in pre- and post- operative Hb mean value $(\mathrm{g} / \mathrm{dL})$ & $1 \pm 0.68 \mathrm{SD}$ & $0.82 \pm 0.58 \mathrm{SD}$ & $0.9 \pm 0.54 \mathrm{SD}$ & $0.89 \pm 0.64 \mathrm{SD}$ \\
\hline $\begin{array}{l}\text { Mean duration time of drenaige removal in patients who } \\
\text { underwent neck dissection (ND) (mL) }\end{array}$ & $2.89 \pm 0.87 \mathrm{SD}$ & $2.63 \pm 0.75 \mathrm{SD}$ & $3.25 \pm 0.81 \mathrm{SD}$ & $2.98 \pm 0.92 \mathrm{SD}$ \\
\hline $\begin{array}{l}\text { Total dreainage production in patients who } \\
\text { underwent ND (mL) }\end{array}$ & $75.94 \pm 47.22 \mathrm{SD}$ & $64.67 \pm 45.92 \mathrm{SD}$ & $88.94 \pm 56.21 \mathrm{SD}$ & $83.23 \pm 38.09 \mathrm{SD}$ \\
\hline Decannulation mean time (days) & $30 \pm 21.5$ SD (12-128) & $26.1 \pm 13.8 \mathrm{SD}(13-70)$ & $31.2 \pm 25.61 \mathrm{SD}$ & $27.9 \pm 11.6 \mathrm{SD}$ \\
\hline $\begin{array}{l}\text { Mean time of removal of naso-gastric-feeding } \\
\text { tube (NGT) (days) }\end{array}$ & $27.4 \pm 18.6 \mathrm{SD}(2-104)$ & $19.4 \pm 13.6 \mathrm{SD}(2-53)$ & $30.3 \pm 19.4 \mathrm{SD}$ & $29.1 \pm 8.8 \mathrm{SD}$ \\
\hline VHI mean value & $43 / 120$ & $38 / 120$ & $41 / 120$ & $43 / 120$ \\
\hline MDADI questionnaire & 84.9 & 86.8 & 83.6 & 84.1 \\
\hline
\end{tabular}


Table 5-Swallowing function analysis under videofluoroscopy vision, performed 3 weeks after surgery.

\begin{tabular}{|c|c|c|c|}
\hline \multirow[b]{2}{*}{ Class } & Group A & Group B & \multirow[b]{2}{*}{$p$ value } \\
\hline & Primary SCPL (90) & Primary SCPL (39) & \\
\hline I & 15 (16.7\%) & 13 (33.3\%) & 0.535 \\
\hline I & 44 (48.9\%) & $18(46.2 \%)$ & \\
\hline III & $31(34.4 \%)$ & $12(30.8 \%)$ & \\
\hline Class & Salvage SCPL (10) & Salvage SCPL (7) & $p$ value \\
\hline I & $2(20 \%)$ & $1(15 \%)$ & 0.637 \\
\hline II & $5(50 \%)$ & $4(57 \%)$ & \\
\hline III & $3(30 \%)$ & $2(28 \%)$ & \\
\hline
\end{tabular}

(1) class I, with no evidence of saliva stagnation; (2) class II, with presence of saliva in the laryngeal vestibule; and (3) class III, with documented inhalation of saliva. Results of this clinical test are collected in Table 5. Neither this swallowing analysis showed statistical significant results.

In addition, postoperative complications were evaluated for each patient during their recovery including: persisting dysphagia, dehiscence of the pexy, postoperative edema of the spared arytenoid unit, single or both, pharyngo-cutaneou fistula, $a b$ ingestis pneumonia, neck abscess and postoperative bleeding. Their results are collected in Table 6.

Among primary SCPL groups, no reduction in postoperative complication rate was found in this comparison analysis among group A (41.1\%) and group B $(41 \%)(p=1)$. Complications that deserve to be counted are the incidence of postoperative arytenoid edema and of $a b$ ingestis pneumonia. The first one presented a higher impact in group B (38.3\%) than in group A (12.2\%) with a statistical significant $p$ value of 0.03 ; while, $a b$ ingestis pneumonia showed a reduction in its incidence in the low-thermal injury device group (2.6\%) than in group A (15.6\%), presenting a $p$ value of 0.038 . The remaining complications did not report any statistical significances.

In salvage SCPL series no statistical significant $p$ values were recorded; two patients experienced the edema of the spared arytenoid unit in the group B (28\%), while in group A there was a total amount of $20 \%$ of complications rate, one of them was a pharyngo-cutaneous fistula (10\%) and the other one the edema of the spared arytenoid unit (10\%).

\subsubsection{Oncological outcomes}

Among the primary treatment groups, the incidence of local recurrence was of $18.9 \%$ in group A and of $20.5 \%$ in group B,

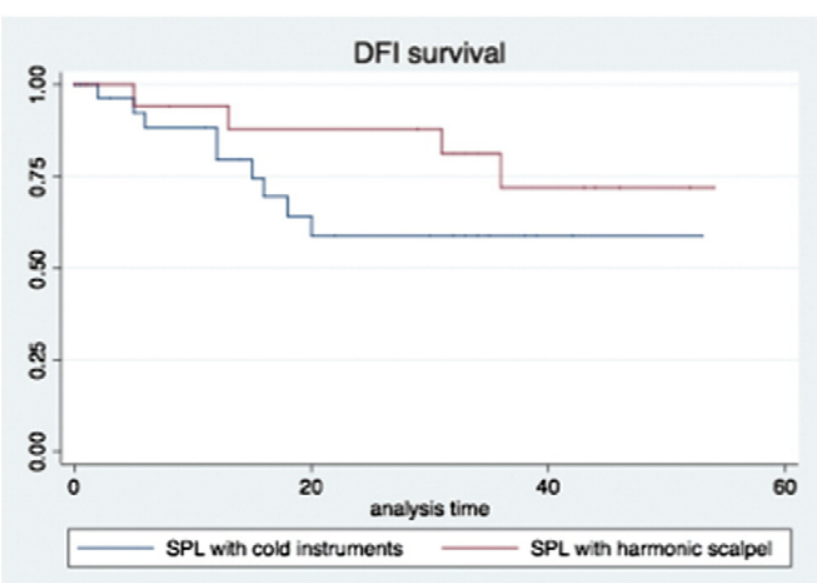

Fig. 1 - Disease-free survival (DFS) analysis by comparing primary SCPL performed by cold instrument (group A) and by harmonic scalpel (group B) $(p=016)$.

without any significant $p$ value $(p=0.27)$ (Table 2). Consequently, salvage total laryngectomy was performed in 13 patients of recurred 17 patients in group $\mathrm{A}(76 \%)$ and in 5 patients of 8 recurred patients in group B (62.5\%), without showing any statistical significance among the two analyzed groups $(p=0.78)$ (Table 2$)$.

Disease-free survival (DFS) ( $p=0.16$ ) (Fig. 1) and actuarial survival (AS) ( $p=1$ ) (Fig. 2) analysis did not evidence any statistical significant results between primary SCPL groups.

Among the salvage treatment groups one patient in group A underwent a totalization of the laryngectomy because of second local recurrence after 20 months. No statistical differences were found in the locoregional control between the two groups.

\subsection{Histological re-evaluation of excised margins from the 129 historical cases by a hypothetical model}

There were 79 negative-margins cases out of 90 in group A; this value reduced by about $18.6 \%$ in group B $(p=0.3089)$, without showing any statistical significant difference in incidence of local recurrence between the two groups. The histopathological analysis showed an increase in number of positive margins, which passed from $5.5 \%$ in group $A$ to a percentage of 12.8 in group $B(p=0.5238)$, and of close-margins $(p=0.0291)$ in the harmonic scalpel group than in group $A$,

Table 6 - Postoperative complications evidenced in the 146 historical series.

\begin{tabular}{|c|c|c|c|c|c|c|}
\hline \multirow[b]{2}{*}{ Complications } & \multicolumn{2}{|l|}{ Primary SCPL } & \multirow[b]{2}{*}{$p$ value } & \multicolumn{2}{|l|}{ Salvage SCPL } & \multirow[b]{2}{*}{$p$ value } \\
\hline & Group A (90) & Goup B (39) & & Group A (10) & Goup B (7) & \\
\hline Dysphagia & $25(27.8 \%)$ & $13(33.3 \%)$ & 0.5 & 0 & 0 & 1 \\
\hline Dehiscence of the pexy & $2(2.2 \%)$ & 0 & 0.12 & 0 & 0 & 1 \\
\hline Edema of one or both spared arytenoid unit & $11(12.2 \%)$ & $15(38.3 \%)$ & 0.03 & $1(10 \%)$ & $2(28 \%)$ & 0.5 \\
\hline Pharyngo-cutaneou fistula & $3(3.3 \%)$ & $1(2.6 \%)$ & 1 & $1(10 \%)$ & 0 & 1 \\
\hline Pneumonia $a b$ ingestis & $14(15.6 \%)$ & $1(2.6 \%)$ & 0.038 & 0 & 0 & 1 \\
\hline Neck abscess & $1(1.1 \%)$ & $2(5.1 \%)$ & 0.217 & 0 & 0 & 1 \\
\hline Postoperative bleeding & $3(3.3 \%)$ & $3(7.7 \%)$ & 0.366 & 0 & 0 & 1 \\
\hline Total & 37 (41.1\%) & $16(41 \%)$ & 1 & $2(20 \%)$ & $2(28 \%)$ & 1 \\
\hline
\end{tabular}




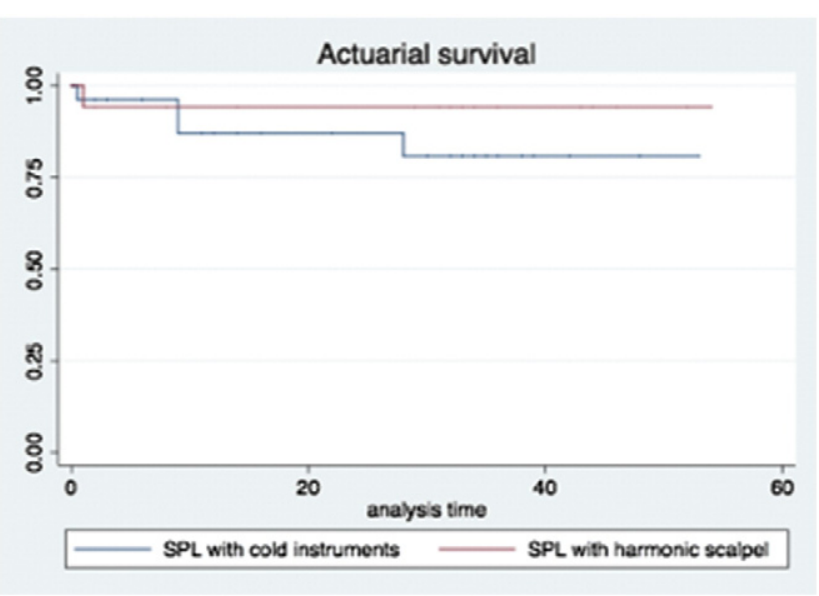

Fig. 2 - Actuarial survival (AS) analysis by comparing primary SCPL performed by cold instrument (group A) and by harmonic scalpel (group B) $(p=1)$.

where they passed from a value of $6.7 \%$ to a value of $17.9 \%$, respectively. Nonetheless, the higher rate of close and positive-margins reported in group B was associated with a statistically no higher incidence of true local recurrences $(p=0.02)$ when compared with group A during follow-up period. Results of this retrospective analysis are summarized in Table 7.

Overall, all positive-cases underwent post-operative radiotherapy, while close-margins were admitted to strict followup. We also documented a better local control during followup, in group B compared to group A, particularly in patients with close/positive-margins report.

Harmonic scalpel probability distribution estimation for each measurement modality was applied, in accordance with published quantitative model of evaluation [15], to the respective distances that were observed for the 5 positive-margins and the 7 close-margin sections from our dataset (Table 7), and this method was also used to derive expected changes in margins status. The $50 \%$ of the sum of tissue retraction (S) and loss of readable tissue (SA) (Table 1 ) best described the margins analyzed; upon this setting, it is expected the following changes would occur if harmonic scalpel was replaced by traditional scalpel: $25 \%$ no change in classification, $40 \%$ of positive margins re-classified as potentially close or negative margins, and $58 \%$ of the total amount of close and positive margins re-classified as negative (Fig. 3).

\section{Discussion}

The critical review of our historical series together with a literature comparison, highlighted the progressive changes in laryngeal open conservative surgery indications and techniques. A comparison among original indications to SCPL [3-8] and recent literature results $[9,15,16]$, supports a clear development and more extended use of this procedure [33-37]. Progression in CAT scan and MRI [10,11], as well new diagnostic endoscopic laryngeal procedures [12-14], allow a millimetric evaluation of tumor extension with a more accurate treatment planning, rendering the surgeon more confident in SCPL option.

Accordingly, here we reported a larger use of SCPL in older patients $(p=0.02)$, T3 staged patients $(p=0.02)$ and for CHEP than for CHP ( $p=0.001)$. These results are in accordance with those reported by other authors in literature $[38,39]$. In addition, SCPL has achieved a progressive more outstanding role as salvage conservative procedure after radiotherapy failure $[40,41]$.

It is well known that open partial laryngectomy technique requires the preservation of specific anatomical units in order to maintain organ function [2,3], and the removal of a few millimeters of unaffected mucosa could compromise the conservative intent. Frozen section margins aim to help surgeons in obtaining disease-free resection [16,17], allowing considering 1-2 $\mathrm{mm}$ of healthy tissue as safe distance to keep far from the tumor front.

Obviously, the changes in the last decade according to extended indications and good functional results, could be due also to improvement in learning curve usually documented for more challenging surgery, although we compared patients surgically treated by different surgeons of different generations.

Because of these changes, thus, we would expect a higher incidence of close and positive margins at the final histopathological report, with an increase risk for patients treated by SCPL. Interestingly, despite the higher number of close and positive margins declared in the harmonic scalpel group study, no higher incidence of local recurrences was reported $(p=0.02)$. This potential discrepancy in group B patients versus group A, might be explained according to a model recently reported by us [15] suggesting that the use of lowthernal-injury device affects the assessment of surgical margins. In accordance with this model, considering its thermal effect on the healthy tissue, we documented a conversion of margins definition approximately $52 \%$.

Additionally, our analyses demonstrated that the use of harmonic scalpel did not offer, in comparison with classic scalpel surgical dissection, any improvements in terms of postoperative

Table 7-Surgical resection margins status of 129 comparative patients study.

\begin{tabular}{|c|c|c|c|}
\hline & Type of margin & $\begin{array}{l}\text { Primary } \\
(90)\end{array}$ & $\begin{array}{l}\text { Recurrence } \\
(18.9 \%)\end{array}$ \\
\hline \multirow[t]{4}{*}{ Group A (90) } & Negative-margin & 79 (87.8\%) & $8(10.1 \%)$ \\
\hline & Positive-margin & $5(5.5 \%)$ & $4(80 \%)$ \\
\hline & Close-margin & $6(6.7 \%)$ & $5(83.3 \%)$ \\
\hline & Type of margin & Primary (39) & Recurrence (20.5\%) \\
\hline \multirow{3}{*}{ Group B (39) } & Negative-margin & 27 (69.2\%) & $5(18.5 \%)$ \\
\hline & Positive-margin & $5(12.8 \%)$ & $2(40 \%)$ \\
\hline & Close-margin & 7 (17.9\%) & $1(14.3 \%)$ \\
\hline \multicolumn{2}{|c|}{$\begin{array}{l}\text { Type of margin } \\
\text { group A vs. group B }\end{array}$} & \multicolumn{2}{|l|}{$p$ value } \\
\hline \multicolumn{2}{|c|}{ Negative-margin } & \multicolumn{2}{|l|}{0.3089} \\
\hline \multicolumn{2}{|c|}{ Positive-margin } & \multicolumn{2}{|l|}{0.5238} \\
\hline \multicolumn{2}{|c|}{ Close-margin } & \multicolumn{2}{|l|}{0.0291} \\
\hline
\end{tabular}




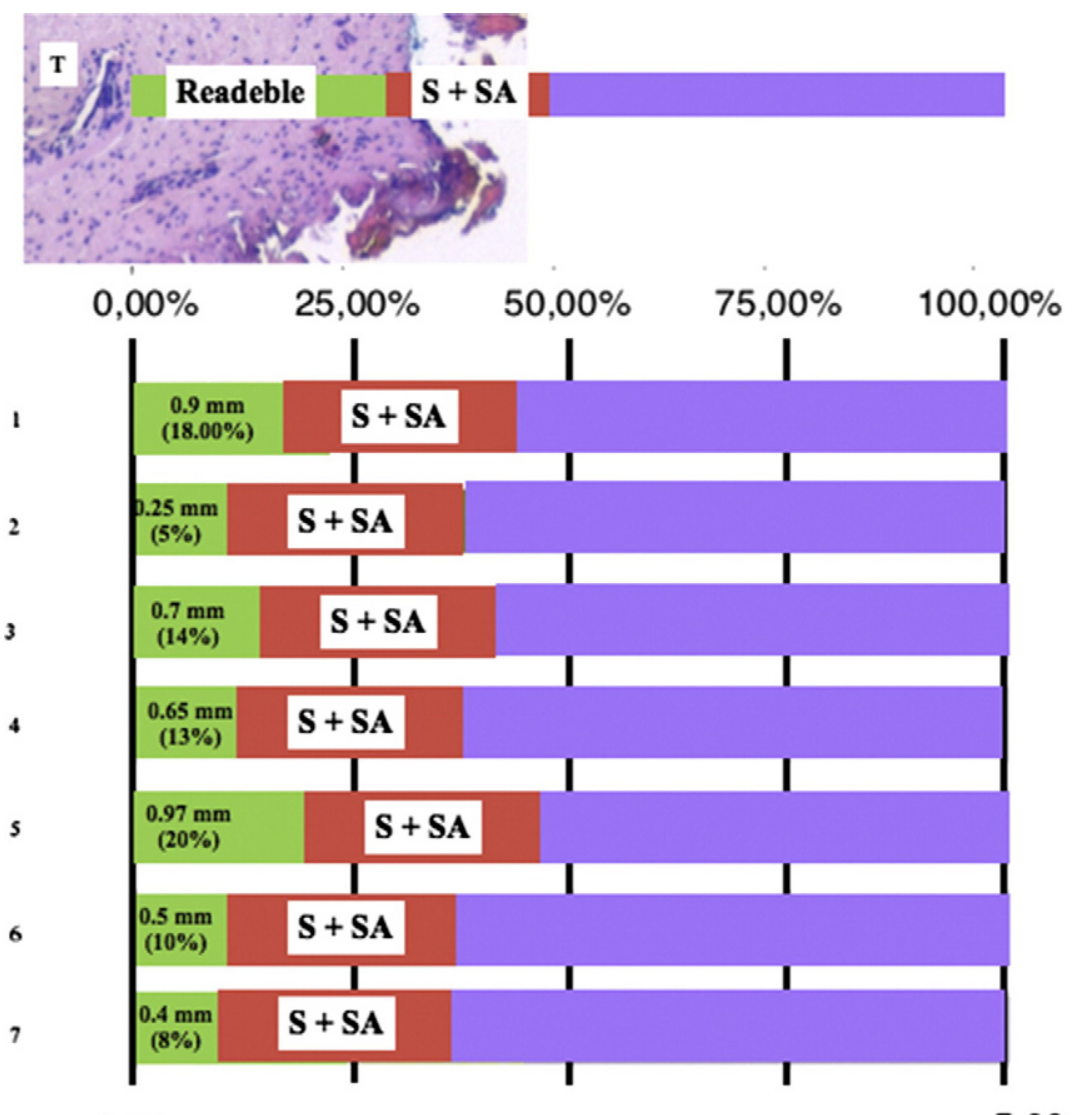

$0,00 \mathrm{~mm}$

\section{$5,00 \mathrm{~mm}$}

Fig. 3 - Probabilities of seven examples of 4 close margins and 3 positive margins change to negative margin status if traditional cold instrument were used for tumor excision. Each margin is associated with a readable area (green), and unreadable area (red) which is the result of the sum of S and SA for the harmonic scalpel, whose mean value is of $1.113 \mathrm{~mm}$, which should be added to the value represented by the green area.

outcomes, even if ultrasonic dissection guaranteed a reduction in operative duration mean time without any rise in risk for developing wound, bleeding or other functional postoperative complications.

\section{Conclusions}

This work demonstrates the increase in conservative surgery indications in older patients, for T3 staged cancer cases and for CHEP than CHP, developed during the last decade, together with the good oncological and functional results achievable in case of salvage surgery after radiotherapy failure. On primary treated patients, we showed that cold instruments and ultrasonic dissections appear to have similar outcomes. On the contrary, harmonic scalpel seems to ensure a better intraoperative bleeding control, with a reduction in operative time, an associated faster oral intake recovery and a significant less incidence in postoperative pneumonia $a b$ ingestis. Nonetheless, even if warm instruments help surgeons in improving surgical accuracy and post-operative outcomes in conservative surgery, we suggest to use cold instruments when few millimeters represent a surgical margin limit for conservative intraoperative decision making, due to the higher rate of close and positive margins reported. Moreover, the avoidance of warm instruments in case of irradiated fields is warranted to reduce the incidence of possible postoperative complications linked to diffuse mucosal edema and late wound healing.

\section{R E F E R E N C E S}

[1] Laccourreye H, Laccourreye O, Weinstein G, et al. Supracricoid laryngectomy with cricohyoidopexy: a partial laryngeal procedure for selected supraglottic and transglottic carcinomas. Laryngoscope 1990;100:735-41.

[2] Majer EH, Rieder W. Technique de laryngectomie permettant de conserver la perméabilité respiratoire (La crico-hyoidopexie). Ann Otolaryngol 1959;76:677-81.

[3] Labayle J, Bismuth R. Laryngectomie totale avec reconstitution. Ann Otolaryngol 1971;88:219-28.

[4] Brasnu DF. Supracricoid partial laryngectomy with cricohyoidopexy in the management of laryngeal carcinoma. World J Surg 2003;27:817-23.

[5] Hofmann-Saguez R. Conservative subtotal laryngectomy. Ann Otolaryngol 1950;67:811-6.

[6] Majer EH, Rieder W. Modification of laryngectomy with preservation of the air passages.

Arch Ohren Nasen Kehlkopfheilkd 1958;173:442-6. 
[7] Alajmo E. La laringectomia subtotala con crico-ioidopessi. Indicazioni e confronto con la laringectoma orizzontale sopraglottica e con la laringectomia totale ricostruttiva. Boll Mal Orecch Gola Naso 1971:1-7.

[8] Piquet JJ, Desaulty A, Decroix G. Supraglottal horizontal laryngectomy in the treatment of supraglottal cancers of the laryngeal border. (Apropos of 104 cases). Ann Otolaryngol Chir Cervicofac 1972;89:35-46.

[9] Gallo A, Manciocco V, Tropiano ML, et al. Prognostic value of resection margins in supracricoid laryngectomy. Laryngoscope 2004;114:616-21.

[10] Becker M. Diagnostic and staging of laryngeal tumors with CT and MRI. Radiologe 1998;38:93-100; Blitz AM, Aygun N. Radiologic evaluation of laryngeal cancer. Otolaryngol Clin North Am 2008;41:697-713.

[11] Beitler JJ, Muller S, Grist WJ, et al. Prognostic accuracy of computer tomography findings for patients with laryngeal center undergoing laryngectomy. J Clin Oncol 2010;28:2318-22.

[12] Bertino G, Cacciola S, Fernandes WB, et al. Effectiveness of narrow band imaging in the detection of pre-malignant and malignant lesions of the larynx. Validation of a new endoscopic clinical classification. Head Neck 2013 [Epub ahead of print].

[13] Piazza C, Del Bon F, Peretti G, et al. Narrow band imgaing in endoscopic evaluation of the larynx. Curr Opin Otolaryngol Head Neck Surg 2012;20:472-6.

[14] Arens C, Dreyer T, Glanz H, et al. Direct and indirect autofluorescence laryngoscopy in the diagnosis of laryngeal cancer and its precursor lesions. Otolaryngol Pol 2004;58: 197-203.

[15] Mannelli G, Meccariello G, Deganello A, et al. Impact of low-thermal-injury devices on margin status in laryngeal cancer. An experimental ex vivo study. Oral Oncol 2014;50:32-9.

[16] Cooley ML, Hoffman HT, Robinson RA. Discrepancies in frozen section mucosal margin tissue in laryngeal squamous cell carcinoma. Head Neck 2002;24:262-7.

[17] Ord RA, Aisner S. Accuracy of frozen sections in assessing margins in oral cancer resection. J Oral Maxillofac Surg 1997;55:663-9.

[18] Paleri V, Thomas L, Basavaiah N, et al. Oncologic outcomes of open conservation laryngectomy for radiorecurrent laryngeal carcinoma: a systematic review and meta-analysis of English-language literature. Cancer 2011;117:2668-76.

[19] Deganello A, Gallo O, De Cesare JM, et al. Supracricoid partial laryngectomy as salvage surgery for radiation therapy failure. Head Neck 2008;30:1064-71.

[20] Jones AS, Hanafi ZB, Nadapalan V, et al. Do positive resection margins after ablative surgery for head and neck cancer adversely affect prognosis? A study of 352 patients with recurrent carcinoma following radiotherapy treated by salvage surgery. Br J Cancer 1996;74:128-32.

[21] Bron L, Brossard E, Monnier P, et al. Supracricoid partial laryngectomy with cricohyoepiglottipexy and cricohyoidopexy for glottic and supraglottic carcinomas. Laryngoscope 2000;110:627-34.

[22] Schroder U, Jungehulsing M, Klussman JP, et al. Cricohoidopexy (CHP) and cricohyoidoepiglottopexy (CHEP). Indications, complications, functional and oncological results. HNO 2003;51:38-45.

[23] Devaiah AK, Shapshay SM, Desai U, et al. Surgical utility of a new carbon dioxide laser fiber: functional and histologic study. Laryngoscope 2005;115:1463-8.
[24] Energy devices overview. http://www.harmonic.com.

[25] Mekeieff M, de la Breteque A, Guerrier B, et al. Voice handicap evaluation after supracrioid partial larynectomy. Laryngoscope 2009;119:746-50.

[26] Castro A, Sanchez-Cuardo I, Bernldez R, et al. Laryngeal function preservation following supracricoid partial laryngectomy. Head Neck 2012;42:162-7.

[27] Schindler A, Mozzanica F, Ginocchio D, et al. Voice-related quality of life in patients after total and partial laryngectomy. Auris Nasus Larynx 2012;39:77-83.

[28] Chen AY, Frankowski R, Bishop-Leone J, et al. The development and validation of a dysphagia-specific quality-of-life questionnaire for pateints with head and neck cancer. Arch Otolaryngol Head Neck Surg 2001;127: 870-6.

[29] Schindler A, Borghi E, Tiddia C, et al. Adaptation and validation of the Italian MD Anderson Dysphagia Inventory (MDADI). Rev Laryngol Otol Rhinol 2008;129:97-100.

[30] Noordally SO, Sohawon S, De Gieter M, et al. A study to determinate the correlation between clinical, fiber-optic endoscopic evaluation of swallowing and videofluoroscopic evaluations of swallowing after prolonged intubation. Nutr Clin Pract 2011;26:457-62.

[31] Wu CH, Hsiao TY, Chen JC, et al. Evaluation of swallowing safety with fiberoptic endoscope: comparison with videofluoroscopic technique. Laryngoscope 1997;107:396-401.

[32] Helliwell TR, Woolgar JA. Datasets for histopathology reports on head and neck neoplasms. 2nd ed. London: Royal College of Pathologists; 2005.

[33] Meier JD, Oliver DA, Varvares MA. Surgical margin determination in head and neck oncology: current clinical practice. The results of an international american head and neck society member survey. Head Neck 2005;27:952-8.

[34] Edge SB, Byrd DR, Compton CC, et al. AJCC Cancer Staging Manual7th ed. ; 2010 [2010, X, 646 p. 130 illus].

[35] Donzelli J, Brady S, Wesling M, et al. Predictive value of accumulated oropharyngeal secrection for aspiration during video nasal endoscopic evaluation of the swallow. Ann Otol Rhinol Laryngol 2003;112:469-75.

[36] Pellini R, Manciocco V, Spriano G. Functional outcome of supracricoid partial laryngectomy with cricohyoidopexy. Arch Otolaryngol Head Neck Surg 2006;132:1221-5.

[37] De Virgilio A, Fusconi M, Gallo A, et al. The oncologic radicality of supracricoid partial laryngectomy with cricohyoidopexy in the treatment of advanced N0-N1 laryngeal squamous cell carcinoma. Laryngoscope 2012;122:826-33.

[38] Mercante G, Grammatica A, Battaglia P, et al. Supracricoid partial laryngectomy in the management of T3 laryngeal cancer. Otolaryngol Head Neck Surg 2013;149:714-20.

[39] Clayburgh DR, Graville DJ, Palmer AD, et al. Factors associated with supracricoid laryngectomy functional outcomes. Head Neck 2013;35:1397-403.

[40] de Vincentiis M, De Virgilio A, Bussu F, et al. Oncological results of the surgical salvage of recurrent laryngeal SCC in a multicentric retrospective series. The emerging role of supracricoid partial laryngectomy. Head Neck 2013 [epub ahead of print].

[41] Spriano G, Pellini R, Romano G, et al. Supracricoid partial laryngectomy as salvage surgery after radiation failure. Head Neck 2002;24:759-65. 